
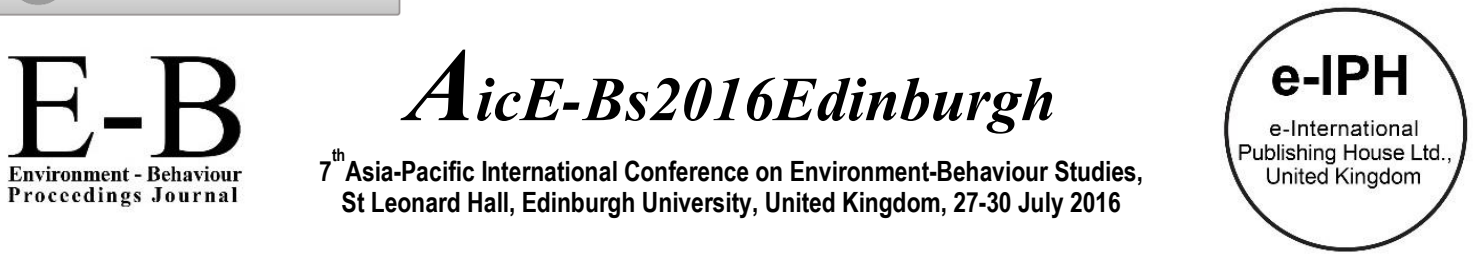

\title{
Urban Design Qualities Related Walkability in a Commercial Neighbourhood
}

\author{
Jenny Ernawati ${ }^{1 \star}$, Muhammad Satya Adhitama22, Surjono ${ }^{3}$, Beta Suryokusumo Sudarmo ${ }^{4}$ \\ ${ }^{124}$ Department of Architecture, Faculty of Engineering, University of Brawijaya, Jl. MT Haryono 167, Malang 65145, Indonesia \\ ${ }^{3}$ Department of Urban and Regional Planning, Faculty of Engineering, University of Brawijaya, JI. MT Haryono 167, Malang 65145, Indonesia
}

\begin{abstract}
This study explored the relations of urban design qualities, the adaptability and people's preference for walking on a commercial street.The research employed survey research method using a self-administered questionnaire applying Likert scale and multiple rating scale techniques. One hundred and three respondents participated in the study. Results of descriptive statistics and correlations analysis indicated the street adaptability may depend on the spatial quality of the street such as legibility, human scale, coherence, and imageability while it does not correlate with the appearance of the street such as transparency, complexity, and enclosure. Meanwhile, people's preference of a street for walking may depend on both qualities.

(C) 2016. The Authors. Published for AMER ABRA by e-International Publishing House, Ltd., UK. This is an open access article under the CC BYNC-ND license (http://creativecommons.org/licenses/by-nc-nd/4.0/).

Peer-review under responsibility of AMER (Association of Malaysian Environment-Behaviour Researchers), ABRA (Association of Behavioural Researchers on Asians) and cE-Bs (Centre for Environment-Behaviour Studies), Faculty of Architecture, Planning \& Surveying, UniversitiTeknologi MARA, Malaysia.
\end{abstract}

Keywords: Urban Design Qualities; Walkability; Commercial Neighbourhood; Adaptability

\section{Introduction}

In recent years, the field of urban design and health science have paid attention to pedestrian communities in urban areas. This situation is due to the awareness of the importance of daily physical activity. The results of previous studies have revealed that heart disease and obesity, for example, can be caused by the body's physical inactivity (Borst, C. H. et al., 2008; Cubukcu, E., 2013; Cubukcu, E. et. al., 2015). One of the daily physical activity most frequently performed is walking, because walking is not only for the purpose of the exercise but also one of the modes of transportation. Previous studies found that walking on a regular basis can reduce the risk of health

\footnotetext{
${ }^{*}$ Corresponding author. Tel.: +628-155-576-2416

E-mail address: jenny.ernawati@fulbrightmail.org
}

2398-4287 @ 2016. The Authors. Published for AMER ABRA by e-International Publishing House, Ltd., UK. This is an open access article under the CC BY-NC-ND license (http://creativecommons.org/licenses/by-nc-nd/4.0/).

Peer-review under responsibility of AMER (Association of Malaysian Environment-Behaviour Researchers), ABRA (Association of Behavioural Researchers on Asians) and CE-Bs (Centre for Environment-Behaviour Studies), Faculty of Architecture, Planning \& Surveying, UniversitiTeknologi MARA, Malaysia.

DOI: http://dx.doi.org/10.21834/e-bpj.v1i4.385 
problems such as heart disease, obesity, high blood pressure, diabetes, depression et cetera (Azmi, D. I. et al., 2012).

Therefore, the physical environment as a place for people's activities has a significant role. Various previous studies show that the built environment design affects people's physical activity in the neighbourhood. Research conducted in the Netherlands by Van Lenthe et al. (2005) for example, found that poor environmental design associated with high probability of community's inactivity. The results of previous studies have revealed relationships between the characteristics of the environment, the physical activity and also the health aspects (Borst, C. H. et al., 2008; Ernawati, 2013, Owen, N. et al., 2004). Therefore, the design of the physical environment that conducive to walking behaviour may be one way to maintain public health (Borst, C. H., 2008, Ernawati, 2013).

That situation shows the importance of the design of the physical environment in public spaces such as streets in the urban area. The street is an urban outdoor space that attracts many people for on-street activities (Samadi, Z. et al., 2015). For regular physical activity, there is no element of the urban environment is more important than a street. The street is a public space that is the most widely used and most accessible by the public. Besides its function as an infrastructure for moving people and vehicles, a street is also working as a social space. In this context, walkability becomes an important concept in urban design.

The literature in urban design further suggests numerous perceptual qualities that may affect the walking environment. Classic literature in urban design provides references of the perceptual quality of urban design. City planners and urban designers assume that perceptual quality of the built environment, the urban design quality, is essential to generate the physical activities such as walking. Unfortunately, the empirical evidence to prove is still very limited. Therefore, this study intended to fill this gap. It is focused on the qualities of urban design that make a street more attractive and walkable.

Moreover, urban change nowadays goes very quickly. The physical urban space, therefore, should be adaptable to accommodate the changing demands of the city's residents. Thus, the physical urban environment must meet the adaptability aspect, which is the ability to adapt to change. The literature in the field of urban design reveals that a high-quality urban design will provide an opportunity for users to adapt quickly to the urban environments as a place of their activities. Which means, a good quality urban design refers to the high quality of the adaptability of the physical environment. In line with this notion, this study purposes to reveal the influence of urban design qualities related walkability to the quality of adaptability.

The literature in the field of urban design and planning in the last few decades further suggest environments or areas with mixed land use. Previous studies have shown that one of the most important characteristics that people look for in a region with mixed land use is its life and diversity. One of them is a commercial area (Brower, 1996). Therefore, this study is intended to assess the quality of urban design of the street in the urban commercial district. The results of the research presented in this paper are the initial part of an ongoing study by the authors that is intended to reveal the influence of urban design quality to the community's preference for a walk. This paper aims to present the results of people's evaluations of the quality of urban design and its influence on the level of adaptability based on the perception of the user community, on one street in the commercial district in downtown Malang, the Agus Salim Street, as the case study.

\section{Literature Review}

\section{Urban Design Quality}

A large body of literature in urban design points numerous perceptual qualities that considered as an outstanding quality of urban design for users of urban space. Among those varying qualities of urban design, the previous study underlined eight urban design quality related walkability that is the most widely discussed and proven empirically (see Ewing \& Handy, 2009). These urban design qualities are imageability, enclosure, human scale, transparency, complexity, coherence, legibility, and the linkage (Ewing et al., 2006; Ewing \& Handy, 2009; Ewing \& Clemente, 2013). 
Imageability is the quality of a place that makes the situation different, easily recognised (recognisable), and memorable. An area is said to have a high imageability if the place has a specific physical elements and arrangement that attract attention, evoke certain feelings, and cause a deep impression. It may be not only the single attribute that causes an imageable street but because of the combination of the various elements present. Lynch (1960) says that the city is imageable when it is well established, made up of different parts, and can be recognised directly by visitors as well as residents. According to him, an imageable city is a city with elements that can be easily identified and grouped in a clear overall pattern. One component of imageability is a landmark. Landmark is a singular feature with a convenient location to make its presence known in the context of the city as a whole. Landmark is an important element in urban design because it serves as a stopping point visually, orientation point, and it is showing the contrast in an urban setting.

Enclosure refers to the degree of "covering" space. The enclosure may happen where the street and public space visually limited by buildings, walls, trees, and other vertical elements. A space that its vertical elements height is proportional compare to the width of the area have qualities such as a room-like (Ewing \& Clemente, 2013). A sense of enclosure formed when lines of sight are limited such that the open space feels like a room that is "closed".

In urban settings, the enclosure formed by restricting street lined with buildings that sustained with relatively the same height, or a row of trees at a certain level. According to Alexander et al. (1977), the total width of the street from building to a building should not exceed the height of the buildings to be able to provide a cozy sense of enclosure. Meanwhile, Jacobs (1993) suggests the proportion of building height to street width is at least 1: 2 . While other town planners recommend the highest proportion of $3: 2$, or at least $1: 6$, to form the enclosure on the street in urban areas.

Human scale refers to the size, texture, and articulation of physical elements that fit the size and proportions of man when walking. The details of the building, the surface of the pedestrian ways, a row of trees, and street furniture are the physical elements that support human scale.

To achieve a real human scale, the width of the building must be proportionate to the height of the building (Ewing \& Clemente, 2013). Some researcher state that any building with more than four floors considered out of human scale, while others provide limits up to six levels and restricts up to three floors only (Ewing \& Clemente, 2013). Trancik (1986) recommend that if the building is high enough, then the lower levels must be seen to accommodate the human scale. For example, the upper floors are made somewhat backward compared to the lower level so that the community still feel the building in human scale when they move in front of the buildings. Other researchers suggest not only the building height but also the width of the building. The trees on the streets can also serve to decrease the scale of high buildings and wide roads. Branches of the trees with leaves that form a canopy can simultaneously give the impression of a relatively small space. Other elements of urban design like paving patterns, street furniture, the setback of high-rise buildings, ornamentation of the building, the distance between the windows and doors and so on can also help the formation of human scale in city spaces (Ewing \& Clemente, 2013 ).

Transparency, in general, refers to a material condition that is translucent to light or air, such as a transparent glass wall. The classic example of transparency is the streets in the commercial area with display windows in front of the shops that invite passersby to see and get into the store. On the other hand, a blank wall or buildings with heavy materials are examples of classic design elements that damage the quality of the transparency. Physical features affecting transparency include walls, windows, doors, fences, landscaping, and openings in the space between the building blocks. Transparency is an important quality to allow interaction between indoor and outdoor activities. Transparency quality is rated high if the internal activity can be made externally or carried on the sidewalk such as outdoor restaurants and shops (Llewelyn \& Davies, 2000; Ewing \& Clemente, 2013).

Complexity refers to the visual richness of a place. Complexity depends on the quality of the physical environment such as variations of buildings, the diversity of architecture and ornamentation, landscape elements, street furniture, signage, and human activities. The complexity associated with the amount of variety that can be clearly seen by the observer (Rapoport, 1990). Humans are very comfortable receiving information with an appropriate level, not too little information but not too much. Pedestrians need a high environmental complexity to feel attracted to walk in the neighbourhood. In essence, complexity refers to a diversity seen in the area. 
Coherence refers to the visual sense of order. The level of integration is affected by the consistency and completeness of scale, character, landscaping, street furniture, and other physical elements. In studies of visual environments, coherence scenery is often measured by individual assessment. For example, Nasar\& Stamps (2009) found that the street is more coherent if the building has a building style which is compatible with the style of buildings in the surrounding neighbourhood. A street is also considered to have coherence if existing buildings not to exceed two times larger than the other buildings in the surrounding. Nasar (1987) found that the observer prefers views of a street with signage that rather complex with a high degree of coherence. If the signage has characteristics that are quite common, then the view of the street will look orderly, logical and predictable by pedestrians, while if otherwise, then the street will look messy or incoherent.

Legibility refers to a condition in which the spatial structure of a place can be understood and can direct the journey with ease. Legibility of a place is determined by a network system that makes it easy for users to provide an environmental orientation. In other words, legibility is the appearance of a lay out background clarity in such a manner so that each part can be easily identified and arranged in a pattern of fused (Lynch, 1960). Legibility refers to the pattern regularity of a street that makes the road easy to understand and "read".

Linkage refers to the physical and visual relationship between the building and the street, a building and a building, the left side of a street and the right side. Rows of trees and zebra cross are examples of elements that create a linkage. The linkage can occur longitudinally along the way, or laterally across the street. Jacobs (1993) suggest connectedness road corridors in urban areas occur at least 90 meters away, while Alexander et al. (1977) suggest there are pedestrian facilities of crossing the street every 60-90 meters. Furthermore, Duany \& Zyberk (1992) limits the size of the building blocks of between 70-180 meters to make sure the distance is still affordable for pedestrians.

\section{Methods}

This research used a quantitative approach, which employed survey research method to study people's evaluation of urban design qualities and its influence on the adaptability in the commercial neighbourhood in downtown Malang, with Agus Salim Street as the case study. Pedestrians on the street were chosen randomly to participate in the survey. A random sample of 120 pedestrians was selected. The researcher went to Agus Salim Street at a variety random times and the five persons met was chosen as respondents. From the 120 respondents, data from 17 participants was discarded because some parts of their questionnaires have no answers. Therefore, there were 103 data used for analysis.

\section{Instruments and Variables}

The primary instrument used in this study is a self-administered questionnaire which consists of three parts. The first section of the questionnaire means to record data of respondents' socio-demographic such as gender, education, and length of stay in the Malang City. The second part of the questionnaire purposed to record people's preference in a walking activity and their perception of adaptability. While the third part of the questionnaire meant to measure people's evaluation of urban design quality of the street. Urban design conditions being studied based on eight aspects of quality invented from the previous studies that representing the perceptual quality of urban design related walkability. These are the enclosure, human scale, transparency, complexity, coherence, legibility, linkage, and imageability (Ewing et al., 2006; Ewing \& Clemente, 2013; Purciel \& Marrone, 2006). The researchers then photographed the physical environment of the street indicating those urban design qualities. The pictures were then used as stimuli in the questionnaire to help respondents in evaluating each quality.

To measure people's perception of the quality of urban design this study employed a Likert Scale method with a five-scale measurement ranging from strongly disagree to strongly agree with number three as the neutral point. Meanwhile to measure community's preference of walking on the street the study used a seven-point multiple rating scales ranging from "Strongly dislike walking on Agus Salim Street" (value=1) to "Strongly like walking on Agus 
Salim Street"(value=7). The quality of adaptability of the street for walking was also measured using a seven-point multiple rating scales with number four as the neutral point, ranging from "low adaptability" (value=1) to "high adaptability" (value=7).

\section{Data Analysis}

This study employed descriptive statistics to identify the quality of urban design and adaptability, while to reveal the relationship between urban design qualities and people's perception of its adaptability and their likability for walking down the street the research conducted Pearson correlation analysis. By carrying out correlation analysis, it can be seen the quality aspects of urban design that have a relationship with and will influence the level of adaptability based on people perception and preference for a walk. All of the data analysis conducted using SPSS software.

\section{The Case Study Site}

Agus Salim Street, the case study site, is located in the centre of the City of Malang, East Java, Indonesia. Commercial activities dominate the street. Commercial buildings such as shopping malls, retail stores, shops, and restaurants dominate the area. This area has developed as a commercial neighbourhood since the Dutch colonial era. Unfortunately, although the street is in the city centres and attracts many people for fulfilling their daily needs, it is not well designed and maintained.

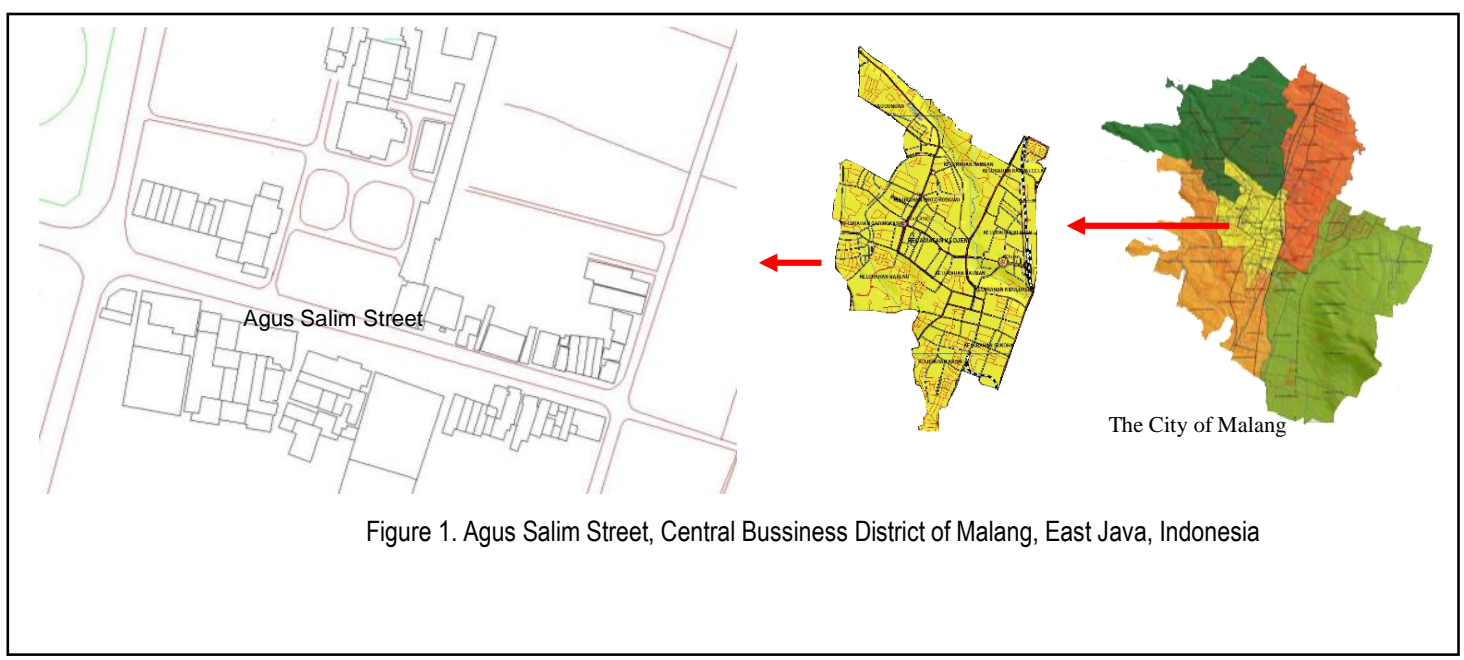



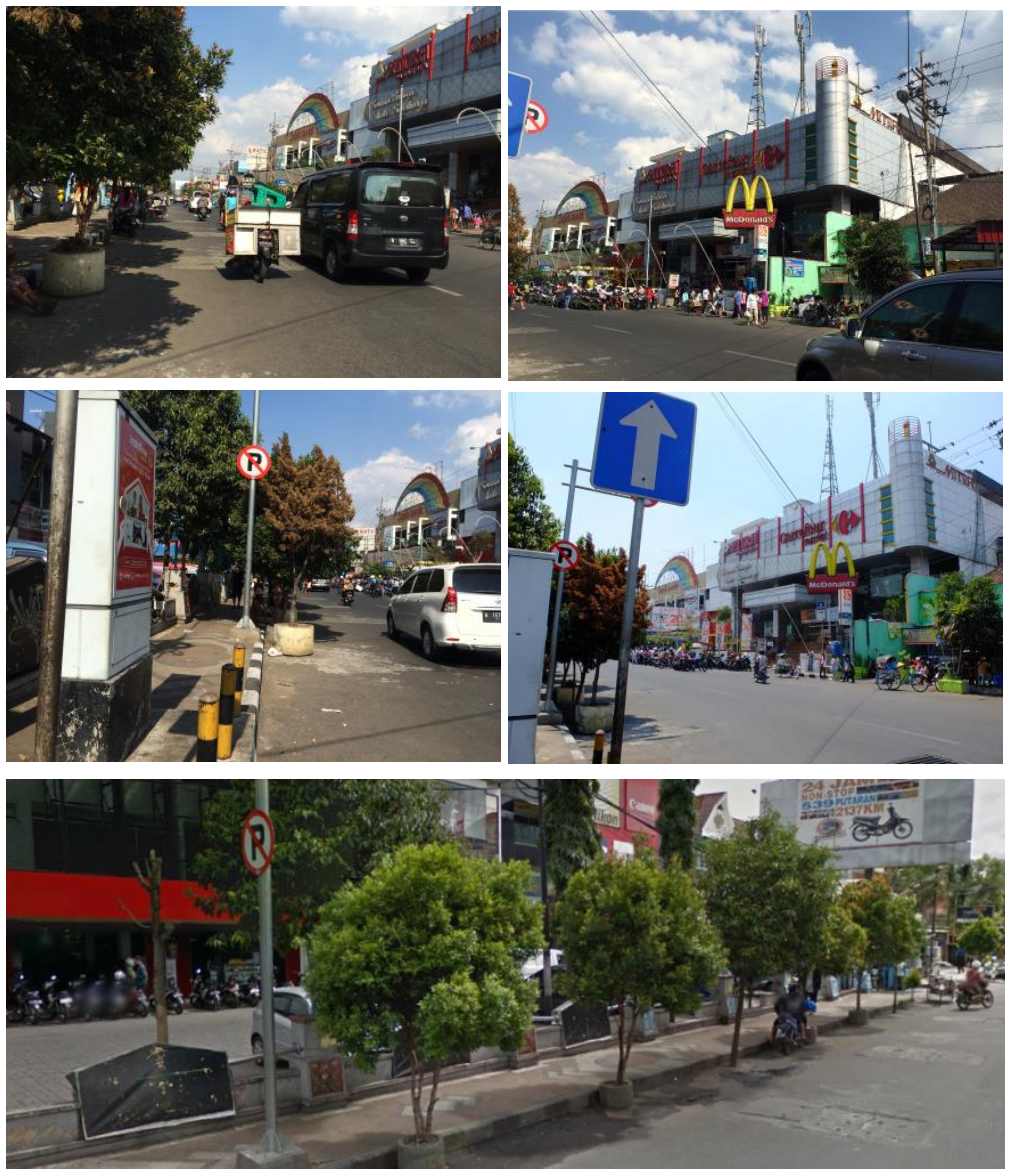

Figure 2. Situation at Agus Salim Street, Central Bussiness District of Malang, East Java,

\section{Results and Discussions}

Respondents in this study consisted of $53 \%$ male and $47 \%$ female, with the majority (83.8\%) aged 18 to 35 years, and $86 \%$ of them are Javanese. Looking at the time of stay in Malang, $53.3 \%$ of respondents had settled in Malang between 10 years to more than 50 years. The conditions show the community that participated in this study are relatively homogenous and have been quite familiar with the city.

The results of the mean score analysis showed the public perception of the adaptability quality of the Agus Salim Street was low (Mean Score $<4$ out of seven scales). This situation means that people judge the quality of the urban design in the corridor of Agus Salim Street provide less opportunity for people to adapt to the walking activity. However, people are still feeling quite like walking down the street Agus Salim (Mean Score $=4.13$ out of five scales). This condition is possible because other factors affect people's preference for a walk on the street other than the quality of adaptability. The research further shows that people evaluate the quality of urban design at the Agus Salim Street, which assessed on five points Likert scale, is relatively low. In average, four quality of the urban design such as enclosure, legibility, transparency, and complexity, rated moderately (Mean Score around 3), while the quality of the human scale, coherence, linkage, and imageability even considered low (Mean <3). This result indicates that the quality of urban design in the Agus Salim Street undervalued by society. Thus, the people walking 
down in the area is due to the need to shop and so forth in the existing shopping area, even though they might not enjoy the neighbourhood because of its insufficient quality.

Previous studies reveal that a high quality of urban design is importance to attract people to walk actively on the street. Urban design literature also shows adaptability as the essential aspect of urban design to accommodate the public demand for a flexible space that allows them to walk comfortably on the street, especially in the commercial district. In this context, to know the variables of the quality of urban design that correlate to the level of adaptability and likability for walking in the Agus Salim Street, the study performed Pearson correlation analysis. Table 1 shows the results of the correlation analysis.

Table 1.Correlations among adaptability, likability and urban design quality.

\begin{tabular}{|c|c|c|c|c|c|c|c|c|c|c|c|}
\hline & & Adaptability & Likeability & Enclosure & Legibility & $\begin{array}{l}\text { Human } \\
\text { Scale }\end{array}$ & Transparency & Complexity & Coherence & Linkage & Imageability \\
\hline \multirow[t]{3}{*}{ Adaptability } & $\begin{array}{l}\text { Pearson } \\
\text { Correlation }\end{array}$ & 1 & $.517^{* *}$ & -.053 & $.304^{* \prime}$ & $.219^{*}$ & .107 & .025 & $.330^{* *}$ & .190 & $.213^{*}$ \\
\hline & $\begin{array}{l}\text { Sig. (2- } \\
\text { tailed) }\end{array}$ & & .000 & .597 & .002 & .026 & .284 & .805 & .001 & .054 & .031 \\
\hline & $\mathrm{N}$ & 103 & 103 & 103 & 103 & 103 & 103 & 103 & 103 & 103 & 103 \\
\hline \multirow[t]{3}{*}{ Likeability } & $\begin{array}{l}\text { Pearson } \\
\text { Correlation }\end{array}$ & $.517^{* *}$ & 1 & -141 & $.314^{* *}$ & .187 & .121 & .036 & $.302^{* *}$ & $.226^{*}$ & $.230^{*}$ \\
\hline & $\begin{array}{l}\text { Sig. (2- } \\
\text { tailed) }\end{array}$ & .000 & & 155 & .001 & .059 & .224 & .716 & .002 & .022 & 019 \\
\hline & $\mathrm{N}$ & 103 & 103 & 103 & 103 & 103 & 103 & 103 & 103 & 103 & 103 \\
\hline
\end{tabular}

${ }^{* *}$. Correlation is significant at the 0.01 level (2-tailed).

*. Correlation is significant at the 0.05 level (2-tailed).

Table 1 shows there are four urban design qualities have a significant relationship with adaptability, i.e. legibility $(p<0.01)$, the human scale $(p<0.05)$, coherence $(p<0.01)$, and imageability $(p<0.05)$. These results mean the four urban design qualities of the street have an influence on the level of convenience for people to adapt to the environment in their walking activities. Furthermore, from those four urban design qualities, coherence has the strongest correlation to the adaptability $(r=0.330, p<0.01)$, which is relatively similar to the strength of the relationship between Adaptability and Legibility $(r=0.304, p<0.01)$. Meanwhile the relationship between adaptability and the Human Scale $(r=0.219, p<0.05)$ relatively has the same strength with the relationship between adaptability and Imageability $(r=0.213, p<0.05)$.

These findings have an implication that society may view the neighbourhood has a quality of adaptability, which is understood as the easiness for people to adapt to an environment to walk, though perhaps the design of the environment is less conducive to walking. However, the results suggest that people may have a perception of the adaptability quality of the street when they evaluate the street as coherence, legible, provide a human scale, and imageable. All of those qualities present an opportunity for people to understand the environment better. The research findings further show that urban design quality that has a correlation to the adaptability quality of the street are those which relate to the spatial dimension. This result is understandable because space act as a container of activities, which in this context is walking. Therefore, adaptability is determined by the condition of the existing spatial aspect in an environment.

The results also showed that the quality of urban design that related to the appearance of the street environment such as transparency, complexity, and enclosure, have no correlation to the quality of adaptability $(p>0.05)$. These results mean that although the condition of those urban design qualities is rated low, it is not necessarily the public assess the street has a little adaptability qualities as well. 
Looking at the correlations between people's preference for walking, which in simple terms is a measure of the like or dislike, and the urban design qualities, Table 1 also shows the dominance of the quality of the spatial dimension of the street such as legibility $(p<0.01)$, coherence $(p<0.01)$, linkage $(p<0.01)$ and imageability $(p<0.01)$. This result shows that although the quality of urban design that emphasises the appearance or the aesthetics of the environment such as transparency, complexity, enclosure and human scale are rated low by the community, people can still like the street to walk as long as the quality of the spatial dimension is good enough.

The results also showed a relatively high correlation between people's preference for a walk and the quality of adaptability $(r=0.517, p<0.01)$, which means, the quality of adaptability of the street is one of the factors that contributes to the formation of people's preference for walking. Therefore, to increase the attractiveness of the street for walkers need to consider the urban design qualities that affect the quality of adaptability and people's preference for a walk.

In conclusion, the adaptability quality of a street environment may depend on the spatial quality of the street such as legibility, human scale, coherence, and imageability while may not influence by the appearance of the neighbourhood such as transparency, complexity, enclosure and linkage. On the other hand, people likability or preference to a street for walking may depend on both qualities, i.e. spatial and non-spatial dimension of the street. Meanwhile, the correlation that exists between adaptability and likability shows that people may like the street for walking because they feel the environment provide the possibility to adapt quickly to accommodate their activities or vice versa, the quality of adaptability of the street make people love to walk. However, this study is still in the early part of a series of on-going research. Therefore, it is necessary to do a similar study on other streets in the commercial neighbourhood to establish the results of this study.

\section{Acknowledgements}

The author is grateful to the Ministry of Research and Higher Education of Indonesia for the research funding.

\section{References}

Ariffin, R. N. R. \&Zahari, R. K. (2013).Perception of the Urban Walking Environments.Procedia - Social and Behavioral Sciences. 105 (2013), 589-597.

Azmi, D. I., Karim, H. A., Amin, M. Z. M. (2012).Comparing the Walking Behaviour between Urban and Rural Residents.Procedia - Social and Behavioral Sciences, 68 (2012), 406-416.

Borst, H. C., Miedema, H. M. E., de Vries, S. I., Graham, J. M. A., van Dongen, J. E. F. (2008). Relationships between street characteristics and perceived attractiveness for walking reported by elderly people. Journal of Environmental Psychology, 28, 353-361.

Brower, S. (1996). Good Neighbourhoods: A Study of in-Town and Suburban Residential Environments. NY: Praeger Publisher.

Cubukcu, E. (2013). Walking for Sustainable Living.Procedia - Social and Behavioral Sciences, 85 (2013), 33-42.

Cubukcu, E., Hepguzel, B., Tumer, B., Onder, Z. (2015). Obesity, Physical Activity, Spatial Environmental Characteristics in Three Types of Residential Settings.Procedia - Social and Behavioral Sciences, 202 (2015), 382-388.

Ernawati, J. (2013). Model Teoritik Hubungan Karakteristik Koridor Jalan Dengan Minat Masyarakat Untuk Berjalan Kak. Laporan Penelitian. FT UB: JurusanArsitektur.

Ewing, R.\& Clemente, O. (2013). Measuring Urban Design: Metrics for Livable Places. Washington: Island Press.

Ewing, R.\& Handy, S. (2009). Measuring the Unmeasurable: Urban Design Qualities Related to Walkability. Journal of Urban Design, 14(1), 6584. 
Ewing, R., Handy, S., Brownson, R. C., Clemente, O., Winston, E.(2006). Identifying and Measuring Urban Design Qualities Related to Walkability. Journal of Physical Activity and Health, 3(1), S223-S240.

Llewelyn-Davies.(2000). Urban Design Compendium. London: English Partnership/Housing Corporation.

Lynch, K. (1960). The Image of the City. Cambridge, MA: Joint Center for Urban Studies.

Nasar, J. L. (1987). Environmental Correlates of Evaluative Appraisals of Central Business District Scenes. Landscape and Urban Planning, 14, 117-130.

Owen, N., Humpel, N., Leslie, E., Bauman, A., Sallis, J. F.(2004). Understanding Environmental Influences on Walking: Review and Research Agenda. American Journal of Preventive Medicine, 27(1), 67-76.

Purciel, M. \& Marrone, E. (2006). Observational Validation of Urban Design Measures for New York City: Field Manual. Active Living Research Program: Robert Wood Johnson Foundation.

Rapoport, A.(1990). History and Precedent in Environmental Design. New York: Plenum.

Samadi, Z., Yunus, R. M., Omar, D., Bakri, A. F. (2015). Experiencing Urban through On-Street Activity. Procedia - Social and Behavioral Sciences, 170 (2015), 653-658.

Trancik, R. (1986). Finding Lost Space - Theories of Urban Design. New York: Van Nostrand Reinhold.

Van Lenthe, F. J., Brug, J. \&Mackenbach, J. P. (2005). Neighbourhood Inequalities in Physical Inactivity: the Role of Neighbourhood Attractiveness, Proximity to Local Facilities and Safety in the Netherlands. Social Science and Medicine, 60, 763-775. 